REVIEW ARTICLE

\title{
Pharmacotherapy in Insomnia
}

\section{Kamlesh Chakravarty and Manjari Tripathi}

Department of Neurology, AlIMS, Delhi

DOI No:10.5958/0974-0155.2015.00018.2

Indian J Sleep Med 2015; 10.4, 131-139

\begin{abstract}
Insomnia is one of the most prevalent sleep disorders. Patients with insomnia tend to have altered quality of life, impaired daytime functioning and increased risk of road traffic accidents. Insomnia is commonly associated with chronic medical conditions and psychiatric illness like depression and anxiety. However, it is now being recognized as an independent disorder. All patients of Insomnia should receive therapy for any medical illness, psychiatric disorders, substance abuse or sleep disorders that might precipitate insomnia. In this review, we discuss the current pharmacotherapeutic options for treatment of insomnia. Research for newer therapeutics for insomnia is often complicated by multifactorial etiology. of insomnia. Understanding the molecular and receptor mechanisms involved in promoting sleep may provide further approaches tothe development of newer drugs.
\end{abstract}

\section{Introduction}

$\mathrm{I}$ nsomnia is the most prevalent sleep disorder in the general population and is commonly encountered in 1 clinical practice. As per International Classification of Sleep Disorder (ICSD)-3 Insomnia is defined as "repeated difficulty in sleep initiation, duration, consolidation, or quality that occurs despite adequate opportunity and circumstances for sleep, and results in some form of daytime impairment" ${ }^{1}$. Approximately 6 $\%$ to $10 \%$ of adults meet the diagnostic criteria for insomnia. It is more common in women and older adults and can occur independently or in association with other

\section{Address for correspondence:}

\section{Dr Manjari Tripathi}

Professor Neurology

NIH Fellow (UCLA)

Department of Neurology

Room No 705, Neurosciences Centre

All India Institute of Medical Sciences, Ansai

Nagar, New Delhi

Email: mtripathiaiims@gmail.com diseases. A questionnaire-based study from Delhi reported the prevalence of insomnia in $28.1 \%$ in adults, $59 \%$ amongst elderly and $17.3 \%$ in children ${ }^{2}$. Another study, undertaken in South India found the prevalence of insomnia to be $18.6 \%$. Insomnia was attributed to depression in $11.7 \%$ and anxiety in $2.5 \%$ patients $^{3}$.

The goal of any treatment for insomnia is, essentially to induce sleep, maintain sleep and feel good the next day. To determine the best treatment options for a patient, it is necessary to determine the type of insomnia. The treatment of insomnia includes both non-pharmacological measures in the form of cognitive behavioral therapy (CBT) and/or pharmacological measures known collectively as hypnotics. CBT includes an educational component (sleep hygiene measures), sleep restriction, stimulus control, cognitive approaches, relaxation therapy and biofeedback ${ }^{4}$. Choice of treatment should be individualized according to patient preferences, availability of behavioral therapy, severity, the impact of insomnia, potential risk and benefits, cost and inconveniences. In this review, we intend to focus on the pharmacotherapy and current guidelines in the management of insomnia. 


\section{Neurotransmitters in sleep and wakefulness:}

There are many neurotransmitters involved in the sleepwake cycle. Sleep-promoting i.e. adenosine, melatonin, galanin, and ã-aminobutyric acid (GABA) and wakefulness-promoting like norepinephrine, orexin, acetylcholine, dopamine, and histamine. Medications prescribed for insomnia work primarily by affecting any one of the three neurotransmitters namely histamine, GABA, and melatonin.

\section{Classification of drugs used in Insomnia}

1. Benzodiazepine Receptor agonist (BzRAs)

a. Benzodiazepines (BZDs)

b. Non-Benzodiazepines (Non-BZDs)

2. Melatonin receptor agonist (MRAs)- Melatonin and Non-melatonin RAs

3. Orexin receptor antagonist

4. Antidepressants

5. Antipsychotics

6. Antihistamines

The classes and medications approved for treatment of insomnia include BzRAs, MRAs, Doxepin, Suvorexant.

\section{Benzodiazepine Receptor agonists (BzRAs)}

Both benzodiazepines and non-benzodiazepine BzRAs act as allosteric modulators of GABA-A receptor/ benzodiazepine receptor $(\mathrm{BzR}) /$ chloride channel complex. By binding with the BzR they potentiate the effect of GABA and cause opening of chloride channels. This leads to an influx of $\mathrm{Cl}^{-}$ions and hyperpolarization of neurons, thus inhibiting its ability to create or propagate an action potential. They reduce the sleep latency (SL), prolong stage 2 sleep, prolong total sleep time (TST) but may reduce rapid eye movement (REM) sleep 5 . Benzodiazepines approved by FDA for thetreatment of insomnia include triazolam, estazolam, temazepam, flurazepam, and quazepam. The primary difference among these medications is their duration of action. Other benzodiazepines are approved in other countries: brotizolam and midazolam (short acting), loprazolam and lormetazepam (intermediate acting), flunitrazepam and nitrazepam (long acting). The pharmacokinetics, duration of action, thedosage of few of the selected drugs is listed in Table 1.

Meta-analyses of randomized, placebo control trials indicate that BZDs reduce SL, a number of awakenings, increase TST, and improve overall sleep quality ${ }^{6-9}$. Diazepam is a long-actingbenzodiazepine but is generally not used in thetreatment of insomnia due to its long duration of action and accumulation of active metabolites. Long-acting BZDs should be avoided in elderly populations due to increased risk of adverse effects.

BZDs are generally safer and well-toleratedincomparison to barbiturates and Tricyclic antidepressants (TCAs). Common adverse effectsinclude residual daytime sedation, drowsiness, light-headedness, psychomotor impairment and/or cognitive impairment and dependence ${ }^{10}$. Although initially efficacious, tolerance seems to occur with these agents after prolonged use of more than 6 months. Rebound insomnia may occur with abrupt discontinuation of short lasting BZDs which typically lasts for 1-2 days ${ }^{11}$. This can be minimized by gradual tapering of the drugs. Physical dependence can occur with long term use but not to the extent of older sedatives. Long-term use has been associated with cognitive decline in elderly ${ }^{12}$, repeated falls ${ }^{13,14}$ and increased the risk of hip fracture ${ }^{15}$. BZDs are contraindicated in pregnancy.

\section{Non- BZD receptor agonists}

Commonly used Non-BZDs for thetreatment of insomnia are zolpidem, zaleplon, eszopiclone and zolpidem extended release.

Zolpidem: It is an imidazopyridine non-benzodiazepine BzRA, and was approved by FDA in 1992 for thetreatment of short-term insomnia. It has now become the most commonly prescribed medication for insomnia.It is available in immediate release, control release, sublingual and spray form. Immediate release form has a half-life of 1.5 to 2.5 hours and its effect lasts up to 8 hours. It is metabolized in liver predominantly by CYP3A4 isoenzymes. Excretion is reduced in the elderly and in patients with hepatic and renal dysfunction. It is indicated for the short-term treatment of insomnia especially sleep onset insomnia. The controlled release form allows immediate release of $60 \%$ of the dose, with the remainder being released at a slower rate. It is useful for both sleep onset insomnia and sleep maintenance insomnia. Sublingual form of Zolpidem was approved 
by FDA in 2011 for maintenance insomnia. The dose for women is $1.75 \mathrm{mg}$ and for men is $3.5 \mathrm{mg}$ taken once per night. Oral spray formulation of zolpidem is equivalent to immediate release tablet form but has a faster onset of action due to faster absorption. It is helpful in patients who have difficulty in swallowing a pill. Zolpidem has been shown to reduce SL, reduce awakenings and increase TST $^{16}$. In a recent study zolpidem, extended release taken for six months improved SL, sleep maintenance, morning sleepiness, and work performance when compared to placebo ${ }^{17,18}$.

Most common side effects are headache, dizziness, and a feeling of a hangover. Headache appears to be dose dependent and occurs in $15-18 \%$ of patients with the recommended dosages. Other side effects include paresthesia, hallucinations, drowsiness, ataxia and sleeprelated behavior disorder. Tolerance is noted at recommended doses. Abrupt discontinuation has been associated with withdrawal symptoms and rebound insomnia.

Safety of zolpidem in pregnancy is not well established. Although there is no absolute contraindications zolpidem should be used with caution in patients with liver disease, chronic obstructive airway disease and patient with depression. An adequate opportunity (7-8 hrs) to sleep is very important as waking up within few hrs of taking zolpidem could lead to automatic behavior and accidents.

\section{Zaleplon}

Zaleplon is a pyrazolopyrimidine hypnotic agent and was approved by FDA in 1999 for thetreatment of shortterm insomnia. It has a very short half-life of about 1 hour, hence primarily effective in patients with sleep onset insomnia. It can also be taken in the middle of the night (MON) insomnia (off-label use) without next day drowsiness or dizziness. Like Zolpidem, it has also been shown to decrease SL and increased TST. However, it is less efficacious in sleep maintenance due to theshort duration of action. Occasional side effects include headache, dizziness, abdominal pain, and somnolence. Abrupt discontinuation does not appear to produce rebound insomnia in adults. The recommended dosage is $10 \mathrm{mg}$ at bedtime for younger patients, and $5 \mathrm{mg}$ for elderly patients.

\section{Eszopiclone}

Eszopiclone is a cyclopyrrolone. It was approved by FDA in 2004 for thetreatment of insomnia. It has got the longest half-life of 6-9 hours among all approved nonBzDs, hence effective for both sleep onset insomnia and sleep maintenance insomnia. It is metabolized by CYP3A4 and 2E1 into active metabolites. The typical starting dose is $2 \mathrm{mg}$ which can be titrated up to $3 \mathrm{mg}$. In elderly and those having chronic liver disease starting dose is $1 \mathrm{mg}$. Like others, it also reduces SL, reduces awakenings and increased TST $^{19}$. Common side effects include metallic taste, headache, dizziness, and parasomnias.

\section{Melatonin receptor agonists: (MRAs)}

Melatonin receptor agonists are divided into two categories: melatonin (natural endogenous ligand) and non-melatonin MRAs. They have different affinities and action on the three different melatonin (MT) receptors namely $\mathrm{MT}_{1}, \mathrm{MT}_{2}, \mathrm{MT}_{3}$. MT 1 agonists induce sleepiness whereas MT2 agonists regulate circadian rhythm.

\section{Melatonin}

Melatonin is a neurohormone secreted by the pineal gland. In humans, it is responsible for temperature regulation, sleep, and circadian rhythms. It has been shown to induce sleep by attenuating the wake fullness promoting impulses in the suprachiasmatic nucleus of the hypothalamus ${ }^{20,21}$. It has a short half-life of 45 to 60 min. In a meta-analysis by Brzezinski et, al melatonin was found to decrease SL by 4 minutes, increased sleep efficiency (SE) by 2.25 and increased TST by $12.8 \mathrm{~min}^{22}$. Currently, melatonin is not approved by FDA for the treatment of insomnia. An extended release preparation has been approved by European Medicines Agency (EMEA) for thetreatment of insomnia in patients above 55 years of age. A double blind placebo controlled trial conducted in Italy showed that food supplementation with $5 \mathrm{mg}$ melatonin, $225 \mathrm{mg}$ magnesium, and 11.25 mg of zinc for 8 weeks significantly improved the sleep quality in patients with primary insomnia ${ }^{23}$. 


\section{Non-Melatonin MRAs}

\section{Ramelteon}

Ramelteon is a selective agonist of $\mathrm{MT}_{1}$ and $\mathrm{MT}_{2}$ receptors within suprachiasmatic nucleus of the anterior hypothalamus. It is rapidly absorbed and has a mean half-life of 1.2 hours. Major isoenzymes involved in themetabolism of Ramelteon is CYP1A2 and about 84\% of the drug is excreted by kidneys after an oral administration. Hence, it would require dose modifications in thepresence of renal and hepatic failure. It is contraindicated in patients taking fluvoxamine which may decrease the metabolism of ramelteon. In a recent meta-analysis that included 11 trials and over 5700 patients found that Ramelteon was associated with significant decrease in subjective SL (-4.6 minutes) and increase in TST (7.3 minutes) in comparison to placebo. However, no significant difference was noted in subjective TST, the number of awakenings, and wake time after sleep onset (WASO) ${ }^{24}$. It was approved by FDA for use in sleep onset insomnia in 2005. Ramelteon has got fewer side effects in comparison to benzodiazepine and nonbenzodiazepines. The most common side effects are somnolence, dizziness, nausea, fatigue, and headache. Elevation of prolactin levels and decreased testosterone levels may occur during the course of treatment, but routine monitoring is not indicated in asymptomatic patients. Ramelteon has got little abuse potential.

\section{Tasimelteon}

Tasimelteon is a newer MRA, approved by FDA forthetreatment of non-24-hour sleep wake disorder, a circadian sleep-wake disorder seen in blind individuals ${ }^{25}$. In phase II and III trials, it has been shown to reduce SL and resetting circadian melatonin rhythm, which may make it suitable for jet lag, shift work, and circadian rhythm sleep disorders. In two randomized, multicentric, blinded, phase III trial tasimelteon $20 \mathrm{mg}$ once nightly were significantly more likely to entrain the circadian pacemaker (SET) and maintain entrainment (RESET) in comparison to placebo $^{26}$.

\section{Agomelatine}

Agomelatine is structurally related to melatonin. It is a potent agonist of $\mathrm{MT}_{1}$ and $\mathrm{MT}_{2}$ receptors and antagonist of the 5-HT2C serotoninergic receptor. Agomelatine in a dose of $25 \mathrm{mg} /$ day has been found to be effective in reducing depressive symptoms in patients with major depressive disorder (MDD). It has been shown to improve all phases of sleep, the overall quality of sleep and has a favorable impact on daytime alertness. It enhances restorative slow wave sleep, however, it doesnotreduce REM sleep ${ }^{27}$. It has a short half-life of 1$2 \mathrm{~h}$ and it is primarily metabolized by cytochrome CYP450 1A2, hence is contraindicated in patients receiving concomitant potent CYP1A2 inhibitors such as fluvoxamine or ciprofloxacin. Common side effect is dizziness.

\section{Orexin receptor antagonist}

Orexin A and B are neuropeptides produced in the lateral hypothalamus. They play a key role in promoting wakefulness and regulating sleep-wake cycle through orexin receptors called OX1 and OX2.

\section{Suvorexant}

Suvorexant is an oral dual orexin receptor antagonist with a half-life of 12 hours. It is metabolized by CYP3A4. In a multicentre, international trial of 781 patients with primary insomnia, it was found to improve both subjective TST and subjective time to sleep onset in comparison to placebo ${ }^{28}$. It is well tolerated. Most common reported adverse effect was daytime somnolence and headache. Other potential side effects include sleepwalking, REM sleep behavior disorder and suicidal ideation. There is potential for increased toxicity when used in combination with CYP3A4 inhibitors. Rebound insomnia may occur with discontinuation of suvorexant. It has got thepotential for dependence and abuse. It was approved by FDA in 2014 at a maximum dose of $20 \mathrm{mg}$ per night. Treatment should be initiated at the lowest dose $(5 \mathrm{mg})$. The role of this drug in insomnia needs to be determined as it has not been compared directly with other therapies for insomnia.

\section{Antidepressants}

The sedating effect of the antidepressant agents is mainly due to their anticholinergic and anti-histaminergic effects. The effects of antidepressant agents mainly come from studies with patients with depression, although optimal hypnotic dosages with clinical efficacy are still unclear. Antidepressants most commonly used to promote sleep 
Table 1: Selected drugs with pharmacokinetics, dosage, and indications

\begin{tabular}{|c|c|c|c|c|c|c|}
\hline Drug & \begin{tabular}{|l|} 
Half-Life \\
in hours
\end{tabular} & $\begin{array}{l}\begin{array}{l}\text { Onset in } \\
\text { hours }\end{array} \\
\end{array}$ & \begin{tabular}{|l|} 
Dosage \\
in $\mathrm{mg}$ \\
\end{tabular} & Metabolism & Indications & Comments \\
\hline \multicolumn{7}{|l|}{ Benzodiazepines } \\
\hline Estazolam & 10 to $24 \mathrm{~h}$ & 0.5 to 1 & $1-2 \mathrm{mg}$ & $\begin{array}{l}\text { CYP3A4 to minimally } \\
\text { active metabolite }\end{array}$ & $\begin{array}{l}\text { Sleep maintenance } \\
\text { insomnia }\end{array}$ & Anxiolytic effect \\
\hline Flurazepam & $\begin{array}{l}40 \text { to } 114 \\
120 \text { to } 160 \\
\text { in adults }\end{array}$ & 0.5 to 1 & 15 to 30 & $\begin{array}{l}\text { CYP3A4 to active } \\
\text { metabolite }\end{array}$ & $\begin{array}{l}\text { Sleep maintenance } \\
\text { insomnia }\end{array}$ & $\begin{array}{l}\text { Significant daytime } \\
\text { residual effect }\end{array}$ \\
\hline Nitrazepam & 24 to 30 & 0.5 to 1 & 5 to 10 & $\begin{array}{l}\text { Non-CYP acetylation in } \\
\text { liver, no active metabolite }\end{array}$ & $\begin{array}{l}\text { Short-term relief } \\
\text { from insomnia }\end{array}$ & $\begin{array}{l}\text { Can cause dependence } \\
\text { and withdrawal } \\
\text { syndrome }\end{array}$ \\
\hline Temazepam & 8 to 15 & 0.5 to 1 & 7.5 to 30 & $\begin{array}{l}\text { Non-CYP glucuronidation } \\
\text { in liver, no active metabolite }\end{array}$ & $\begin{array}{l}\text { Sleep maintenance } \\
\text { insomnia }\end{array}$ & Daytime residual effect \\
\hline Triazolam & 2 to 5 & 0.25 to 0.5 & 0.125 to 0.25 & $\begin{array}{l}\text { CYP3A4, no active } \\
\text { metabolite }\end{array}$ & Sleep onset insomnia & $\begin{array}{l}\text { Associated with } \\
\text { rebound insomnia }\end{array}$ \\
\hline Quazepam & 28 to 84 & 0.5 to 1 & 7.5 to 15 & $\begin{array}{l}\text { CYP3A4 and non- } \\
\text { CYP metabolism in liver } \\
\text { to active metabolites }\end{array}$ & $\begin{array}{l}\text { Sleep maintenance } \\
\text { insomnia }\end{array}$ & Anxiolytic effect \\
\hline \multicolumn{7}{|c|}{ Non- Benzodiazepines } \\
\hline Zaleplon & $1 \mathrm{hr}$ & 0.1 to 0.25 & 5 to 10 & CYP3A4 metabolism & Sleep onset insomnia & $\begin{array}{l}\text { Minimal rebound } \\
\text { insomnia }\end{array}$ \\
\hline Zolpidem IR & 1.5 to 4.5 & 0.1 to 0.25 & 5 to 10 & CYP3A4 metabolism & $\begin{array}{l}\text { Sleep onset insomnia } \\
\text { or Sleep maintenance } \\
\text { insomnia }\end{array}$ & $\begin{array}{l}\text { Contraindicated in } \\
\text { severe hepatic } \\
\text { impairment }\end{array}$ \\
\hline Zolpidem CR & $\begin{array}{l}1.5 \text { to } 4.5 \\
\text { (sustained } \\
\text { release } \\
\text { preparation) }\end{array}$ & 0.1 to 0.25 & 6.25 to 12.5 & CYP3A4 metabolism & $\begin{array}{l}\text { Sleep onset insomnia } \\
\text { or Sleep maintenance } \\
\text { insomnia }\end{array}$ & \\
\hline Zolpidem SL & $\begin{array}{l}1.5 \text { to } 6.5 \\
\text { (sublingual) }\end{array}$ & 0.1 to 0.25 & 1.75 to 3.5 & CYP3A4 metabolism & $\begin{array}{l}\text { Sleep maintenance } \\
\text { insomnia (middle of } \\
\text { the night dose) }\end{array}$ & \\
\hline Zolpidem spray & 1.5 to 8.5 & 0.1 to 0.25 & 5 to 10 & CYP3A4 metabolism & Sleep onset insomnia & \\
\hline Eszopiclone & 6 to 9 & $0.1 \mathrm{t} 00.25$ & 1 to 3 & $\begin{array}{l}\text { CYP3A4 to active } \\
\text { metabolite }\end{array}$ & $\begin{array}{l}\text { Sleep onset insomnia } \\
\text { and Sleep maintenance } \\
\text { insomnia }\end{array}$ & \\
\hline Zopiclone & 5 to 7 & 0.1 to 0.25 & 3.75 to 7.5 & CYP3A4 and CYP2E1 & Sleep onset insomnia & $\begin{array}{l}\text { Potential carcinogenic } \\
\text { effect. Not approved } \\
\text { by FDA }\end{array}$ \\
\hline \multicolumn{7}{|l|}{ Others } \\
\hline Ramelteon & $\begin{array}{l}1 \text { to } 2.5 \\
2 \text { to } 5 \\
\text { (active } \\
\text { metabolite) } \\
\end{array}$ & 0.3 & $8 \mathrm{mg}$ & CYP1A2 & Sleep onset insomnia & $\begin{array}{l}\text { Should be administered } \\
\text { with caution with } \\
\text { CYP1A2 inhibitors }\end{array}$ \\
\hline Doxepin & $\begin{array}{l}15 \text { (drug) } \\
31 \text { (Active } \\
\text { metabolite) } \\
\end{array}$ & 3.5 & 3 to $6 \mathrm{mg}$ & CYP2D6 & $\begin{array}{l}\text { Sleep maintenance } \\
\text { insomnia }\end{array}$ & $\begin{array}{l}\text { Avoid with MAO } \\
\text { inhibitors }\end{array}$ \\
\hline Suvorexant & 12 & $0.5-2$ & $10 \mathrm{mg}$ & CYP3A4 & $\begin{array}{l}\text { Sleep onset insomnia } \\
\text { and Sleep maintenance } \\
\text { insomnia }\end{array}$ & $\begin{array}{l}\text { Avoid with CYP3A4 } \\
\text { inhibitors }\end{array}$ \\
\hline
\end{tabular}

Abbreviations: IR- Immediate release, CR- Controlled release, SL- sublingual 
are:

i. Tricyclic antidepressants (TCAs): amitriptyline, trimipramine, and doxepin

ii. Heterocyclic antidepressants: Trazodone and Mirtazapine

Out of these, doxepin is the only antidepressant to be approved by FDA for the treatment of insomnia.

\section{Amitriptyline}

Sedative action of amitriptyline is due to its anticholinergic, antihistaminic, and anti-alfal actions. The sedative effects are immediate and precede the antidepressant effects, and decrease after a few week of treatment. Several small studies of amitriptyline for depression or anxiety disorder with coexistent insomnia suggest some improvement in sleep quality. The recommended dose ranges from $12.5 \mathrm{mg}$ to $50 \mathrm{mg}$.

\section{Trimipramine}

The sedating effect of trimipramine is attributed to its anticholinergic property. It is the only effective antidepressant drug against insomnia, that doesnot alter the sleep architecture. It has been shown to increase sleep efficiency, without altering TST $^{29}$. The usual starting dose is $25 \mathrm{mg}$ three times a day, which is gradually increased to $150-200 \mathrm{mg} /$ day. Discontinuation has not been linked to rebound insomnia. It should not be given to patients with or within 2 weeks of treatment with monoamine oxidase (MAO) inhibitors.

\section{Doxepin}

Doxepin is the only antidepressant to be approved by FDA for insomnia. It has been found to improve SL, asignificant reduction in WASO as well as improvements in TST and $\mathrm{SE}^{30}$. Usual dosage for insomnia is $3 \mathrm{mg}$ and $6 \mathrm{mg}$. It has a good safety profile in elderly patients. It is very useful for sleep maintenance and early morning awakenings in the elderly population. Most common adverse effects are fatigue, dizziness, light-headedness, dry mouth, constipation, and urinary retention. It should not be used in patients with hypersensitivities to other TCAs, glaucoma and those taking MAO inhibitors within 14 days. In India, $10 \mathrm{mg}$ and $12 \mathrm{mg}$ doses are also available.

Indian Journal of Sleep Medicine (IJSM), Vol. 10, No. 4, 2015

\section{Trazodone}

Trazodone is a 5-HT2 receptor antagonist and a weak serotonin reuptake inhibitor. Until 2002, it was one of the most commonly prescribed drugs for insomnia. In a parallel group study comparing trazodone $(50 \mathrm{mg})$ and zolpidem $(10 \mathrm{mg})$ with placebo, trazodone was found to improve both self-reportedSL and TST,although to a lesser extent in comparison to zolpidem. However, this effect was noted only in the first 2 weeks of therapy. Prescribed dose is $50 \mathrm{mg} / \mathrm{day}$. Common side effects include orthostatic hypotension, dry mouth, constipation, and light-headedness.

\section{Mirtazapine}

Mirtazapine is an atypical antidepressant. The sedating properties of Mirtazapine are partly due to the antagonism of type 1 histaminergic receptors. In depressed patients, it has been found to improve sleep architecture and sleep efficiency without suppressing REM sleep ${ }^{31,32}$. The recommended dose range from $7 \mathrm{mg}$ to $30 \mathrm{mg}$.

Despite their sleep-promoting effects, routine use of sedating antidepressants other than low-dose doxepin for thetreatment of insomnia is not recommended because the sedating effects tend to be short-lived.

\section{Antipsychotics}

Antipsychotics have been used inthetreatment of insomnia, however, there are few trials establishing their efficacy and all have potentially significant adverse effects. Routine use of antipsychotics for thetreatment of insomnia is not recommended. Quetiapine and Olanzapine are often used off-label for treatment of insomnia in patients with psychiatric disorders. Antagonism of Type 1 histaminergic and 5HT2C receptors accounts for the sedative properties. They have been found to improve TST and SE, reduced N1 and increased N2 and N3 sleep in schizophrenic patients ${ }^{33}$. Serious side effects include tardive dyskinesia and akathisia.

\section{Antihistamines}

Diphenhydramine is a sedating antihistamine which is used in many over- the-counter sleep medications. There is little evidence to suggest that diphenhydramine improves insomnia, but due to long half-life, it may cause 
next day sedation. Other side effects include decreased alertness, delirium, dry mouth, urinary retention, constipation, blurred vision and increased intraocular pressure. Routine use of diphenhydramine for insomnia is not recommended.

\section{Indian Guidelines on pharmacotherapy}

\section{Indications for pharmacotherapy in Insomnia}

There is no clear-cut consensus on the use of pharmacological agents for the treatment of insomnia. However, they can be used in the following conditions. They should be used in the short-term only.

1. Acute stress

2. Predictable stress

3. Shift work

4. Jet Lag

5. Certain medical disorders

6. Acute flare-ups of chronic insomnia

\section{Role of pharmacotherapy in acute onset insomnia}

Consensus of major practices and guidelines for primary insomnia suggests the following preferences:

1. Short-intermediate acting Non-BzRAs including zolpidem, zopiclone, eszopiclone and zaleplon $(Z$ drugs)

2. When there is a failure of a "Z-drug", consider alternative short-intermediate acting BzRAs or Ramelteon.

3. A sedating antidepressant may be considered as first line treatment in cases with co-existing psychiatric disorder e.g. depression/anxiety. Examples include trazodone, amitriptyline, doxepin, and mirtazapine.

4. Combined therapy should be avoided unless the patient is not responding to monotherapy.

\section{Pharmacotherapy in special population groups}

\section{Insomnia in Pregnancy}

1. Sedatives and hypnotics: zolpidem, diphenhydramine, gabapentin

2. Antidepressants: amitriptyline, doxepin, trazodone

\section{Insomnia in children and Adolescents}

Alpha agonists are most commonly prescribed insomnia medication for children and adolescents with attention deficit hyperactivity disorder, mental retardation, and developmental disabilities. Trazodone is most commonly used in children with co-existent mood and anxiety disorder.

\section{Insomnia in elderly}

The etiology and magnitude of insomnia due to changes in circadian rhythms, co-morbid conditions, and effective pharmaceutical agents are not well documented. Melatonin confers a better safety profile in comparison to traditional sedative-hypnotics. Safety parameters should be given paramount importance while choosing an agent for elderly.

\section{Insomnia in medical co-morbidities}

1. In patients with a chronic renal disease, short-term eszopiclone in low dose is the drug of choice. Other Non-BzRAs are also indicated but must be used with caution.

2. In pulmonary disease and severe obstructive sleep apnea, the use of BZDs is contraindicated.

3. In patients with psychiatric comorbidities, sedating antidepressants and antipsychotics are the first-line of treatment. In patients with depression with insomnia, either a sedating antidepressant (e.g mirtazapine $30-45 \mathrm{mg}$ ) or a combination of low dose sedating and non-sedating antidepressant or a combination of effective non-sedating antidepressant plus BzRA hypnotic may be considered. 


\section{Practical strategy for prescribing pharmacotherapy of insomnia}

The overall strategy to prescribe pharmacotherapy to a patient of insomnia depends on symptom patterns, duration of symptoms, treatment goals, history of past treatment failures, side effects and co-morbid conditions.

1. Sleep onset insomnia: ramelteon or zaleplon.

2. Sleep maintenance insomnia: zolpidem, zolpidemcr, eszopiclone, temazepam

3. Elderly patient with impaired hepatic metabolism: Lower dose of drugs to be used

4. Anxiety predominant insomnia: traditional BZDs, temazepam, eszopiclone. If not effective lorazepam or clonazepam could be used. If the above treatment is partially effective sedating antidepressant (e.g trazodone, low dose doxepin, amitriptyline) may be added. A sedating antipsychotic (e.g quetiapine) can be used as a last resort in case of a co-existing mental disorder.

\section{Conclusion}

Although chronic insomnia is very difficult to diagnose and to treat, clinicians should recognize the importance of determining the cause of insomnia as multiple factors can contribute insomnia in one patient. Long-term use of hypnotics is not advisable for thetreatment of primary chronic insomnia. With the exception of zolpidem extended-release, eszopiclone, Ramelteon, low dose doxepin, the indications for FDA-approved insomnia are all short-term. To date, minimal safety and efficacy data are available regarding hypnotic use for more than 6 months. While selecting a drug patient-related factors like nature of insomnia symptoms, age, response to previous treatment and affordability should be considered.

\section{References}

1. American Academy of Sleep Medicine. The International Classification of Sleep Disorder. Third Edition. Darien IL, American Academy of Sleep Medicine;2014.

2. Suri JC, Sen MK, Adhikari T.Epidemiology of Sleep Disorders in the Adult population of Delhi: A Questionnaire-Based Study. Indian J Sleep Medicine 2008;3.4,128-137.

3. Panda S, Taly AB, Sinha S, Gururaj G, Girish N, Nagaraja D. Sleep-related disorders among a healthy population in South India. Neurol India. 2012;60(1):68-74.
4. Montgomery P, Dennis J. A systematic review of nonpharmacological therapies for sleep problems in later life. Sleep Med Rev. 2004;8(1):47-62.

5. Drugs for insomnia. Treat Guidel Med Lett. 2009;7(79):2326.

6. Buscemi N, Vandermeer B, Friesen C, et al. The efficacy and safety of drug treatments for chronic insomnia in adults: a meta-analysis of RCTs. J Gen Intern Med. $2007 ; 22(9): 1335-1350$.

7. Holbrook AM, Crowther R, Lotter A, Cheng C, King D. Meta-analysis of benzodiazepine use in the treatment of insomnia. CMAJ Can Med Assoc J JAssocMedicale Can. 2000; $162(2): 225-233$.

8. Nowell PD, Mazumdar S, Buysse DJ, Dew MA, Reynolds CF, Kupfer DJ. Benzodiazepines and zolpidem for chronic insomnia: a meta-analysis of treatment efficacy. JAMA. $1997 ; 278(24): 2170-2177$.

9. Krystal AD. A compendium of placebo-controlled trials of the risks/benefits of pharmacological treatments for insomnia: the empirical basis for U.S. clinical practice. Sleep Med Rev. 2009;13(4):265-274.

10. Roth T, Roehrs TA. A review of the safety profiles of benzodiazepine hypnotics. J Clin Psychiatry. 1991;52 Suppl:38-41.

11. Mendelson WB. Clinical distinctions between long-acting and short-acting benzodiazepines. J Clin Psychiatry. 1992;53 Suppl:4-7; discussion 8-9.

12. Paterniti S, Dufouil C, Alpérovitch A. Long-term benzodiazepine use and cognitive decline in the elderly: the Epidemiology of Vascular Aging Study. J ClinPsychopharmacol. $2002 ; 22(3): 285-293$.

13. Avidan AY, Fries BE, James ML, Szafara KL, Wright GT, Chervin RD. Insomnia and hypnotic use, recorded in the minimum data set, as predictors of falls and hip fractures in Michigan nursing homes. J Am Geriatr Soc. $2005 ; 53(6): 955-962$.

14. Kelly KD, Pickett W, Yiannakoulias N, et al. Medication use and falls in community-dwelling older persons. Age Ageing. 2003;32(5):503-509.

15. Ray WA, Griffin MR, Downey W. Benzodiazepines of long and short elimination half-life and the risk of hip fracture. JAMA. $1989 ; 262(23): 3303-3307$.

16. Scharf MB, Roth T, Vogel GW, Walsh JK. A multicenter, placebo-controlled study evaluating zolpidem in the treatment of chronic insomnia. J Clin Psychiatry. $1994 ; 55(5): 192-199$.

17. Krystal AD, Erman M, Zammit GK, Soubrane C, Roth T, ZOLONG Study Group. Long-term efficacy and safety of zolpidem extended-release $12.5 \mathrm{mg}$, administered 3 to 7 nights per week for 24 weeks, in patients with chronic primary insomnia: a 6-month, randomized, double-blind, placebo-controlled, parallel-group, multicenter study. Sleep. 2008;31(1):79-90.

18. Erman M, Guiraud A, Joish VN, Lerner D. Zolpidem extended-release $12.5 \mathrm{mg}$ associated with improvements in work performance in a 6-month randomized, placebocontrolled trial. Sleep. 2008;31(10):1371-1378. 
19. Krystal AD, Walsh JK, Laska E, et al. Sustained efficacy of eszopiclone over 6 months of nightly treatment: results of a randomized, double-blind, placebo-controlled study in adults with chronic insomnia. Sleep. 2003;26(7):793-799.

20. Hughes RJ, Sack RL, Lewy AJ. The role of melatonin and circadian phase in age-related sleep-maintenance insomnia: assessment in a clinical trial of melatonin replacement. Sleep. 1998;21(1):52-68.

21. Haimov I, Lavie P, Laudon M, Herer P, Vigder C, Zisapel N. Melatonin replacement therapy of elderly insomniacs. Sleep. 1995; 18(7):598-603.

22. Brzezinski A, Vangel MG, Wurtman RJ, et al. Effects of exogenous melatonin on sleep: a meta-analysis. Sleep Med Rev. 2005;9(1):41-50.

23. Rondanelli $\mathbf{M}$, Opizzi A, Monteferrario F, Antoniello $\mathrm{N}$ Manni R, Klersy C. The effect of melatonin, magnesium, and zinc on primary insomnia in long-term care facility residents in Italy: a double-blind, placebo-controlled clinical trial. J Am Geriatr Soc. 2011;59(1):82-90.

24. Kuriyama A, Honda $M$, Hayashino $Y$. Ramelteon for the treatment of insomnia in adults: a systematic review and meta-analysis. Sleep Med. 2014;15(4):385-392.

25. Hardeland R. Tasimelteon, a melatonin agonist for the treatment of insomnia and circadian rhythm sleep disorders. CurrOpinlnvestig Drugs LondEngl 2000. 2009;10(7):691 701

26. Lockley SW, Dressman MA, Licamele L, et al. Tasimelteon for non-24-hour sleep-wake disorder in totally blind people (SET and RESET): two multicentre, randomised, doublemasked, placebo-controlled phase 3 trials. Lancet Lond Engl. 2015;386(10005):1754-1764.
27. Quera Salva M-A, Vanier B, Laredo J, et al. Major depressive disorder, sleep EEG and agomelatine: an openlabel study. Int J NeuropsychopharmacolOffSci J CollInt Neuropsychopharmacol CINP. 2007;10(5):691-696.

28. Michelson D, Snyder E, Paradis E, et al. Safety and efficacy of suvorexant during 1-year treatment of insomnia with subsequent abrupt treatment discontinuation: a phase 3 randomised, double-blind, placebo-controlled trial. Lancet Neurol. 2014;13(5):461-471.

29. Hohagen F, Montero RF, Weiss E, et al. Treatment of primary insomnia with trimipramine: an alternative to benzodiazepine hypnotics? Eur Arch Psychiatry ClinNeurosci. $1994 ; 244(2): 65-72$

30. Krystal AD, Durrence HH, Scharf $M$, et al. Efficacy and Safety of Doxepin $1 \mathrm{mg}$ and $3 \mathrm{mg}$ in a 12-week Sleep Laboratory and Outpatient Trial of Elderly Subjects with Chronic Primary Insomnia. Sleep. 2010;33(11):15531561.

31. Winokur A, DeMartinis NA, McNally DP, Gary EM, Cormier JL, Gary KA. Comparative effects of mirtazapine and fluoxetine on sleep physiology measures in patients with major depression and insomnia. J Clin Psychiatry. 2003;64(10):1224-1229.

32. Schittecatte $M$, Dumont $F$, Machowski R, Cornil C, Lavergne $F$, Wilmotte J. Effects of mirtazapine on sleep polygraphic variables in major depression. Neuropsychobiology. 2002;46(4):197-201

33. Salin-Pascual RJ, Herrera-Estrella M, Galicia-Polo L, Laurrabaquio MR. Olanzapine acute administration in schizophrenic patients increases delta sleep and sleep efficiency. Biol Psychiatry. 1999;46(1):141-143. 